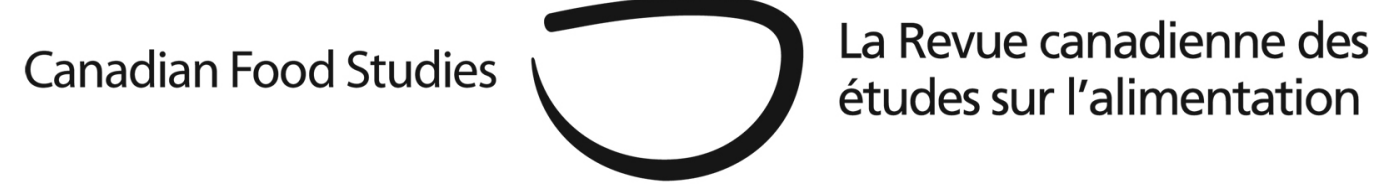

Review Article

\title{
Tackling household food insecurity: An essential goal of a national food policy
}

\author{
Naomi Dachner and Valerie Tarasuk* \\ Department of Nutritional Sciences, University of Toronto
}

\begin{abstract}
Eradicating household food insecurity is key to the articulated vision of a national food policy that aims to promote healthy living and safe food for families across the country. Household food insecurity refers to the insecure or inadequate access to food due to financial constraints. Despite federal commitments to improve the situation, food insecurity in Canada increased between 2007-08 and 2011-12. It currently affects more than four million Canadians, and the situation is particularly grave in Indigenous communities. Food security takes a toll on individuals' health and well-being, and on our healthcare system. The social epidemiology of household food insecurity shows it to be inextricably linked to the social and economic circumstances of households. Federal and provincial policy interventions that improve the financial circumstances of very low income households have yielded reductions of up to 50 percent in household food insecurity prevalence, proving that effective, evidence-based policy responses are possible. Yet, high prevalence rates persist. A national food policy represents an opportunity to address food insecurity, but doing so requires the integration of policy actions, both horizontally-across social, economic, health and agriculture domains, and vertically—across the three levels of government. In addition, performance targets must be established, and ongoing monitoring and evaluation mechanisms implemented, to ensure that policies and programs meant to address food insecurity actually have a meaningful impact.
\end{abstract}

Keywords: Food insecurity, public policy, income, Canada 


\section{The state of food insecurity in Canada}

\section{Scale of the problem}

It is imperative that the 1.7 million households in Canada ( Tarasuk, Mitchell, \& Dachner, 2014) currently facing food insecurity be brought into the articulated vision of a National Food Policy that promotes the enjoyment of healthy and safe food for families across the country (Office of the Prime Minister, 2015). To realize the benefits associated with a long-term vision for the health, environmental, social, and economic goals related to food in Canada, Canadians must have the means to achieve adequate and secure access to sufficient food.

Food security is typically defined as the state that exists when "all people, at all times, have physical and economic access to sufficient, safe and nutritious food to meet their dietary needs and food preferences for an active and healthy life”(Agriculture and Agri-Food Canada, 1998). Household food insecurity is often presented as the absence of food security, but population-level assessments of this condition have focused on a much more tightly circumscribed set of experiences of food deprivation and dietary compromise rooted in financial constraints. Household food insecurity, as the term has been operationalized in the Canadian context, refers to the inadequate or insecure access to sufficient food because of financial constraints.

Questions related to food insecurity have been included on national population health surveys in Canada for more than two decades now. Household food insecurity is currently monitored through the Household Food Security Survey Module (HFSSM) administered on Statistics Canada's Canadian Community Health Survey. The HFSSM captures a household's experience of food insecurity through a series of questions ranging from concerns about running out of food before there is more money to buy more, to the inability to afford a balanced diet, to going hungry, missing meals, and in extreme cases, not eating for a whole day because of a lack of food and money for food (Health Canada, 2007). The questions differentiate between the experiences of adults and children because of an abundance of research showing that when families are struggling to manage with scare resources, adults will deprive themselves of food as a way free up supplies for their children.

Household food insecurity now affects more than 4 million Canadians (Tarasuk et al., 2014), a number 4 - 5 times higher than the number reported to be using food banks (Loopstra \& Tarasuk, 2015). Further, the problem is not diminishing. Despite federal commitments to improve the situation (i.e. Rome Declaration on World Food Security and the World Food Summit Plan of Action) (Mah, Hamill, Rondeau, \& McIntyre, 2014), the prevalence of household food insecurity in Canada has increased significantly, with over 600,000 more people affected between 2007-08 and 2011-12 (Figure 1). These statistics understate the true prevalence of food insecurity in Canada because First Nations communities are not included in the Canadian Community Health Survey. 
Household Food Insecurity in Canada

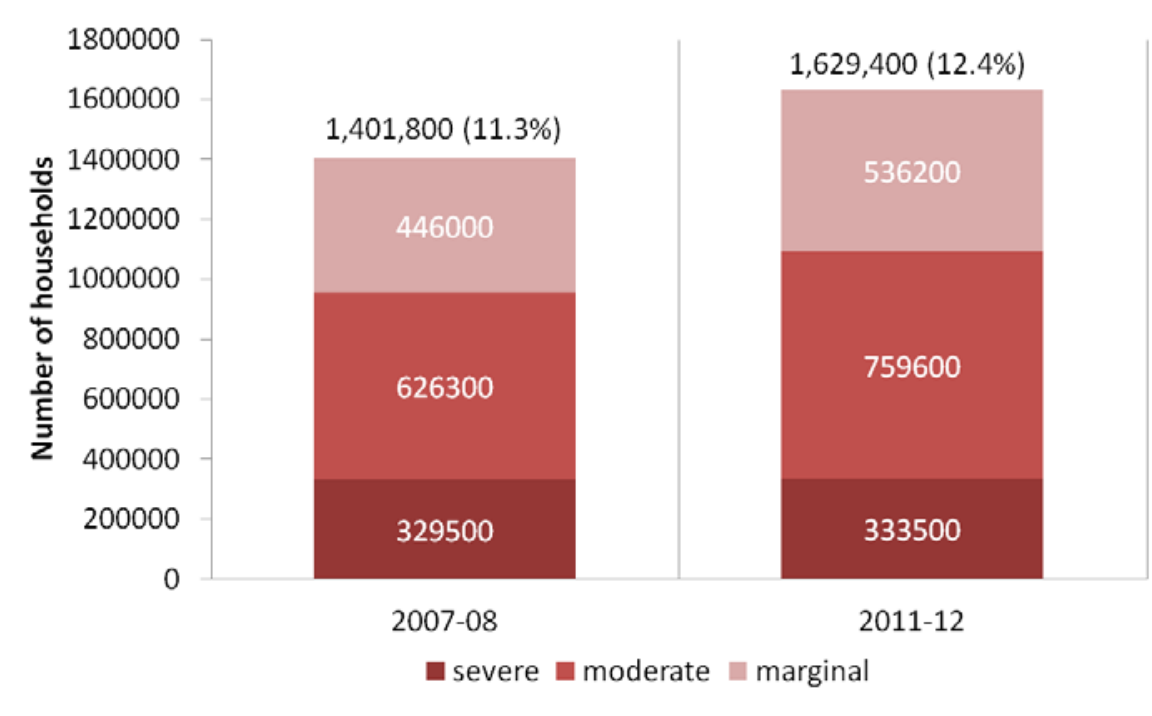

Figure 1: Household food insecurity in Canada, 2007-08 and 2011-12 (Source: PROOF, 2018)

Source: Statistics Canada, Canadian Community Health Survey 2007, 2008, 2011, 2012.

\section{Household food insecurity} by province \& territory

Figure 2: Household food insecurity in 2012 by province and territory (Source: Tarasuk et al., 2014)

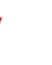
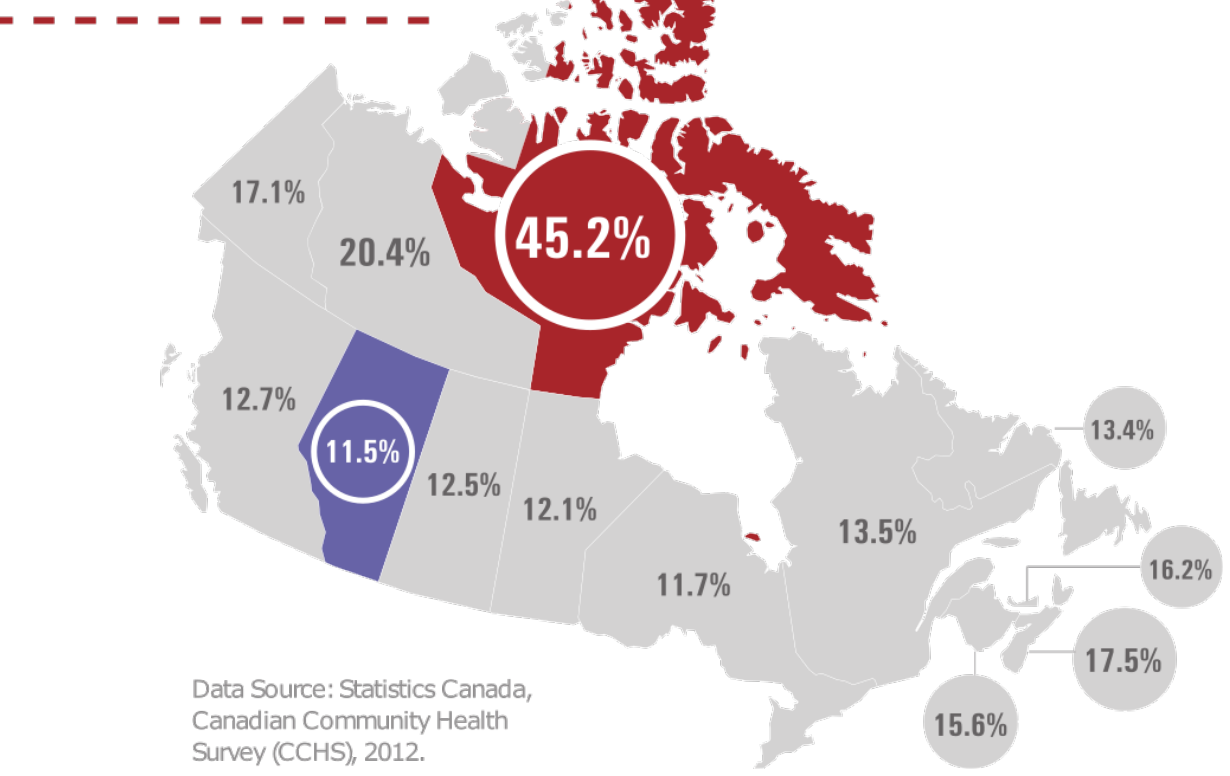

Food insecurity is prevalent in every province and territory, but rates are highest in the Maritimes and the territories (Figure 2). Food insecurity is a particularly serious problem in northern and Indigenous communities. Based on data from the 2014 Canadian Community 
Health Survey, 46.8 percent of households in Nunavut and 24.1 percent in the Northwest Territories reported food insecurity; almost two-thirds of children under the age of 18 in Nunavut were in food-insecure households ( Tarasuk, Mitchell, \& Dachner, 2016). The earlier Inuit Health Survey charted a food insecurity prevalence of 70 percent (Huet, Rosol, \& Egeland, 2012). According to the 2012 First Nations Information Governance Centre (FNIGC), 54.2 percent of households in the 2008/10 First Nations Regional Health Survey, a survey of First Nations adults living on reserve and in northern First Nations communities, were food-insecure (40.1 percent moderate, and 14.1 percent severe).

\section{Nutrition and health impacts}

Analyses of population survey data, coupled with smaller in-depth studies of particularly vulnerable groups, have yielded a solid understanding of the nutrition and health impacts of food insecurity on Canadians, clearly establishing household food insecurity as a potent social determinant of health. Food insecurity is associated with poorer diet quality (Danyliw, Vatanparast, Nikpartow, \& Whiting, 2011; Kirk et al., 2015; Kirkpatrick \& Tarasuk, 2008; Mark, Lambert, O'Loughlin, \& Gray-Donald, 2012), and increased risk of micronutrient inadequacies (Kirkpatrick et al., 2015; Kirkpatrick \& Tarasuk, 2008; McIntyre et al., 2003; Vatanparast, Calvo, Green, \& Whiting, 2010). In addition, there is a substantial body of literature documenting disturbingly high levels of nutritional vulnerability among food-insecure adults and children in Canada's North (Egeland, Johnson-Down, Cao, Sheikh, \& Weiler, 2011; Egeland, Pacey, Cao, \& Sobol, 2010; Huet et al., 2012; Pirkle et al., 2014).

Apart from its effects on nutritional well-being, household food insecurity in Canada is associated with increased risk of negative physical and mental health problems, and among children, it is linked to poorer educational outcomes. Young children exposed to hunger are more likely to have mental health problems (e.g. hyperactivity and inattention) (Melchior et al., 2012), and a recent study of grade five students in Nova Scotia documented poorer academic achievement among those exposed to severe levels of household food insecurity (Faught, Williams, Willows, Asbridge, \& Veugelers, 2017). Exposure to "hunger" in childhood increases the risk of developing various chronic health conditions (e.g. asthma, depression) in adolescence and early adulthood, independent of family poverty or other socio-demographic characteristics (Kirkpatrick, McIntyre, \& Potestio, 2010; McIntyre, Wu, Kwok, \& Patten, 2017). It has also been associated with increased likelihood of dropping out of high school (McIntyre, Kwok, \& Patten, 2017). Among adults, food insecurity is associated with increased likelihood of numerous chronic mental and physical conditions (Che \& Chen, 2001; Davison, Marshall-Fabien, \& Tecson, 2015; Jessiman-Perreault \& McIntyre, 2017; Muldoon, Duff, Fielden, \& Anema, 2012; Tarasuk, Mitchell, McLaren, \& McIntyre, 2013; Vozoris \& Tarasuk, 2003; Willows, Veugelers, Raine, \& Kuhle, 2011), and it impedes the management of chronic diseases (Anema, Chan, Weiser, Montaner, \& Hogg, 2013; Cox et al., 2016; Gucciardi, DeMelo, , \& Stewart, 2009; Jessiman-Perreault \& McIntyre, 2017; Marjerrison, Cummings, Glanville, Kirk, \& Ledwell, 
2010). The gravity of the health consequences, especially those associated with severe food insecurity, is evident in the high burden that food insecurity places on our healthcare system (Fitzpatrick et al., 2015; Tarasuk et al., 2015; Tarasuk, Cheng, Gundersen, De Oliveira, \& Kurdyak, 2018). Research in Ontario has shown that over the course of a year, the healthcare costs for adults in severely food insecure households are more than double that of those in food secure situations ( Tarasuk et al., 2015).

\section{What drives vulnerability to food insecurity?}

Household food insecurity is tightly linked to household resources. Research into the household circumstances that mitigate or exacerbate risk indicates that food insecurity is primarily the product of household income, including both the amount and stability/security of the income (Leete \& Bania, 2010; McIntyre, Dutton, Kwok, \& Emery, 2016a), but it is also influenced by households' access to savings and assets (chief among these being home ownership) (Guo, 2011; Huang, Guo, \& Kim, 2010; Leete \& Bania, 2010; McIntyre, Wu, Fleisch, \& Emery, 2015) and costs of living (Emery et al., 2012; Gregory \& Coleman-Jensen, 2013; Nord, Coleman-Jensen, \& Gregory, 2014; Sriram \& Tarasuk, 2016). Other household characteristics repeatedly documented to increase risk include reliance on social assistance, Aboriginal status, lower education, and being a lone-parent female-led family (Che \& Chen, 2001; Li, Dachner, \& Tarasuk, 2016; McIntyre, Connor, \& Warren, 2000; McIntyre et al., 2015; Tarasuk \& Vogt, 2009; Willows, Veugelers, Raine, \& Kuhle, 2009)—all markers of profound social and economic disadvantage. Employment does not guarantee household food security (McIntyre, Bartoo, \& Emery, 2012). As shown in Figure 3, in 2012, almost two-thirds of all food insecure households in the country were reliant on salaries and wages (Tarasuk et al., 2014).

Figure 3: Food insecure households' main source of income, 2012 (Source: Tarasuk et al., 2014)

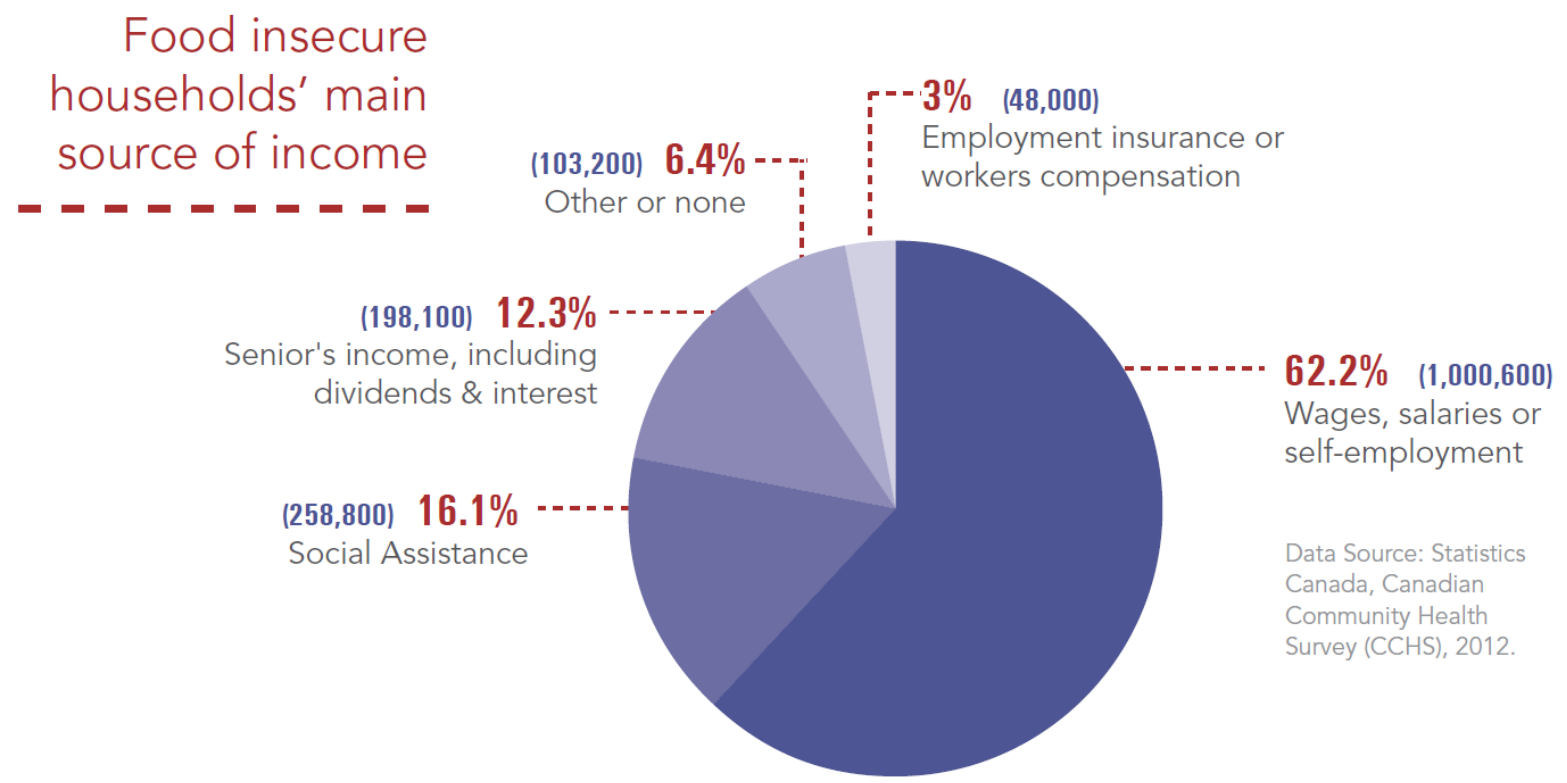


Consistent with the understanding of risk that has emerged from analyses of crosssectional population survey data, a growing body of research indicates that household food insecurity status is impacted by policies that improve the adequacy and stability of the incomes of low income households. The strongest evidence comes from research into the relative protection against household food insecurity enjoyed by Canadian seniors ( Emery, Fleisch, \& McIntyre, 2013; McIntyre et al., 2016a). The risk of food insecurity among low-income adults in their fifties drops by more than 50 percent when they become eligible for an old-age pension ( McIntyre et al., 2016a). The protection afforded by this guaranteed annual income is not only a function of the amount of income provided by Old-Age Security and the Guaranteed Income Supplement (which together provide more than double the income of someone on welfare in most provinces), but also the predictability and stability of this income ( McIntyre et al., 2016a).

Further evidence of the sensitivity of household food insecurity to policy interventions that affect household finances comes from an examination of the effects of the poverty reduction strategy implemented in Newfoundland and Labrador between 2006 and 2012 (Province of Newfoundland and Labrador, 2014). In tandem with a series of substantial improvements to the province's income assistance program, the food insecurity prevalence among recipients fell, from 60 percent in 2007 to 34 percent in 2012 (Loopstra, Dachner, \& Tarasuk, 2015). It is impossible from the available data to delineate the specific changes that precipitated this drop, but among the policy reforms enacted, the province increased Income Support rates, indexed them to inflation, and raised the earnings and liquid assets exemptions for people on Income Support (Loopstra et al., 2015). Consistent with the findings in Newfoundland and Labrador, a small decrease in food insecurity was documented among social assistance recipients in British Columbia immediately following a very modest one-time increase to benefits in that province (Li, Dachner, \& Tarasuk, 2016). These studies suggest that the extraordinarily high rates of food insecurity among social assistance recipients stem from inadequate benefit levels.

The reduction in food insecurity charted among families with young children following the introduction of the Universal Child Care Benefit (Ionescu-Ittu, Glymour, \& Kaufman, 2015) provides further evidence of the capacity for income interventions to ameliorate this problem. This benefit, introduced in 2006, gave all families \$100 per month for each child under the age of six. In the years that followed, it yielded a 25 percent decrease in food insecurity among families who received it, with even greater reductions among lower income and single-parent families (Ionescu-Ittu et al., 2015). The Universal Child Care Benefit was discontinued in 2016, when the Canada Child Benefit came into effect. How this new benefit will impact food insecurity rates among families with children remains to be seen.

Food insecurity rates are also sensitive to macroeconomic conditions. In Canada, we have evidence that prevalence is impacted by heating cost inflation ( Emery et al., 2012), increases in the rate of unemployment (Sriram \& Tarasuk, 2015), and shelter costs (Sriram \& Tarasuk, 2016). Additionally, temporal trends in the US suggest that food insecurity rates are sensitive to shifts in food prices (Gregory \& Coleman-Jensen, 2013; Nord et al., 2014). Although analogous research has not yet been conducted in Canada, the last decade here has been characterized by an 
unprecedented rise in food prices (Charlebois et al., 2014; Rollin, 2013). For those whose incomes are indexed to inflation or augmented by periodic cost of living increases, the effects of rising prices have been buffered. But for households most at risk of food insecurity (e.g. those reliant on social assistance or low-waged and possibly precarious work), such protection is likely non-existent.

While there is an abundance of evidence linking food insecurity to households' social and economic circumstances, this condition appears unrelated to food literacy or food retail access. National population survey data indicate that the probability of household food insecurity is not associated with individuals' skills in grocery shopping, food preparation, or cooking (Huisken, Orr, \& Tarasuk, 2016). Adults in food insecure households appear acutely aware of the nutritional compromises they make as they struggle to accommodate the food preferences and nutrition needs of family members while working within a limited budget (Beagan, Chapman, \& Power, 2017; Dachner, Ricciuto, Kirkpatrick, \& Tarasuk, 2010; Frank, 2015; Hamelin, Beaudry, \& Habicht, 2002; Williams et al., 2012). Consistent with these findings are studies suggesting that interventions designed to improve the nutrition knowledge or cooking skills of those experiencing food insecurity have limited capacity to lessen problems rooted in abject poverty (Engler-Stringer \& Berenbaum, 2005, 2007; Engler-Stringer, Stringer, \& Haines, 2011; Hamelin, Mercier, \& Bedard, 2010, 2011; Loopstra \& Tarasuk, 2013; Tarasuk, 2001). There has been less study of the relationship between household food insecurity and the food retail environment, but studies conducted in Toronto and Montreal found that food insecurity was unrelated to one's physical access to grocery stores (Kirkpatrick \& Tarasuk, 2010; Perez, Roncarolo, \& Potvin, 2017).

In contrast to evidence in the general population, issues of food insecurity appear tightly intertwined with the food environment for Indigenous peoples in Canada (Council of Canadian Academies, 2014). In northern Indigenous communities, food insecurity occurs in the context of diminishing access to traditional foods (Council of Canadian Academies, 2014; Egeland et al., 2011; Ford \& Beaumier, 2011), concerns about affordability of food through market and traditional channels (Action Canada, 2013/14; Lambden, Receveur, Marshall, \& Kuhnlein, 2006; Veeraraghavan et al., 2016), and ongoing questions about the effectiveness of the federal food subsidy program, Nutrition North Canada, in improving food access (Galloway, 2014, 2017). Within Indigenous communities, households most at risk of food insecurity appear to be those with the least economic resources (as indicated, for example, by a reliance on social assistance (Pirkle et al., 2014), highlighting the centrality of purchasing power to food access through market channels, but also the increasing need for financial resources to engage in traditional food acquisition practices. Community food security initiatives grounded in local experiences and working to improve food access to the most vulnerable are now well-established in many northern communities, but the limits of these efforts to address severe problems of household food insecurity are well recognized (Seed, Lang, Caraher, \& Ostry, 2014; Wong \& Hallsworth, 2016). 
In sum, household food insecurity is a serious problem in Canada, taking a very real toll on individuals' health and well-being. After more than two decades of research and populationlevel measurement, the social epidemiology of this problem is well understood, and there is a growing body of evidence demonstrating the sensitivity of this problem to federal and provincial policy interventions that impact household resources. Yet, high prevalence rates persist.

\section{The role of a national food policy}

A national food policy represents a critical opportunity to address food insecurity in this country. National leadership is badly needed to spearhead effective and enduring policy responses. However, the policy levers to address food insecurity in Canada transcend the conventional boundaries (scope of work) of Agriculture and Agri-food Canada, a ministry whose primary focus is policies and programs related to the growth and development of the agriculture and agrifood sectors in Canada (Government of Canada, 2016). Addressing food insecurity requires coordinated action across several federal ministries and all three levels of government. Thus it challenges Canada to move toward a “joined up” food policy (MacRae, 2011).

Although Canada has a long history of income transfer programs to support lower income households, these programs have not been explicitly designed to support household food security and none are accountable to this outcome. The aforementioned examinations of income-related policies on food insecurity prevalence have all been conducted by academic researchers, not government departments. As awareness of problems of hunger in our midst has grown, government actions have been limited to measures to support ad hoc, community-based initiatives, in particular the food charity system (McIntyre, Lukic, Patterson, Anderson, \& Mah, 2016b). These include “Good Samaritan” laws that absolve corporations of liability for the health and safety of the food they donate, tax credits for farm donations, and public funds supporting food bank infrastructure. There is also continued public investment in community gardens, kitchens, meal programs, and food buying programs, partly based on the argument that they mitigate problems of food insecurity. This piecemeal approach has persisted despite legislators' clear recognition of the relationship between food insecurity and structural issues associated with poverty ( McIntyre et al., 2016b; McIntyre, Patterson, Anderson, \& Mah, 2016c).

Research on the impact of policy interventions that address low income is clear: In Canada, we have seen declines of up to 50 percent in household food insecurity prevalence and severity among vulnerable groups as a result of policy reforms that have improved their financial circumstances (Loopstra et al., 2015; McIntyre et al., 2016a). Thus effective policy responses are possible. However, more direct policy evaluations by the federal, provincial, and territorial governments are required to develop effective, evidence-based strategies to prevent household food insecurity. We need studies to determine the specific levels of income needed to minimize risks of food insecurity, identify the most effective mechanisms to ensure income adequacy (e.g., whether through a mix of targeted income supplements and universal benefits or through the 
implementation of a basic income guarantee), and delineate the other services and programs required to support household food security. Ontario’s Basic Income Pilot (Government of Ontario, 2017) should yield some insight into the food security effects of setting a modest income floor for working-aged adults, but this small-scale social experiment is only one step. Examination of the food insecurity effects of the full spectrum of federal, provincial, and territorial policies and programs that determine income adequacy and security for households at the bottom end of the income spectrum is needed to design effective policy responses. This includes evaluating the impact of the Canada Child Benefit on families' food insecurity, but also assessing the effects of minimum wage levels, Employment Insurance, and targeted benefits for low-waged, precarious workers to determine how best to address food insecurity in the labour force. A framework and action plan rooted in policy integration, both horizontally (across policy domains), and vertically (across the three levels of government) is required to reduce the prevalence and severity of household food insecurity in Canada.

Forging an effective response requires the alignment of policy objectives across departments. Whereas much of the responsibility for policies that impact household incomes lie within the federal departments of finance, employment and social development, housing and energy policies are also relevant to this problem. Within Agriculture and Agri-Food Canada, there is a need for ongoing monitoring of food costs to ensure that the after-tax (and after-shelter) incomes of our most vulnerable households are sufficient for them to meet basic food needs, and that vital income support programs are insulated from inflationary pressures. Additionally, given the strong intersection of household food insecurity with low-waged, seasonal, and precarious employment, measures to improve the labour conditions of those in the agri-food sector are part of addressing food insecurity (Weiler, McLauglin, \& Cole, 2017).

Figure 4: Food insecurity in Canada, households reliant on social assistance and all households (Source: PROOF, 2017)

Food Insecurity in Canada, $2012^{1}$

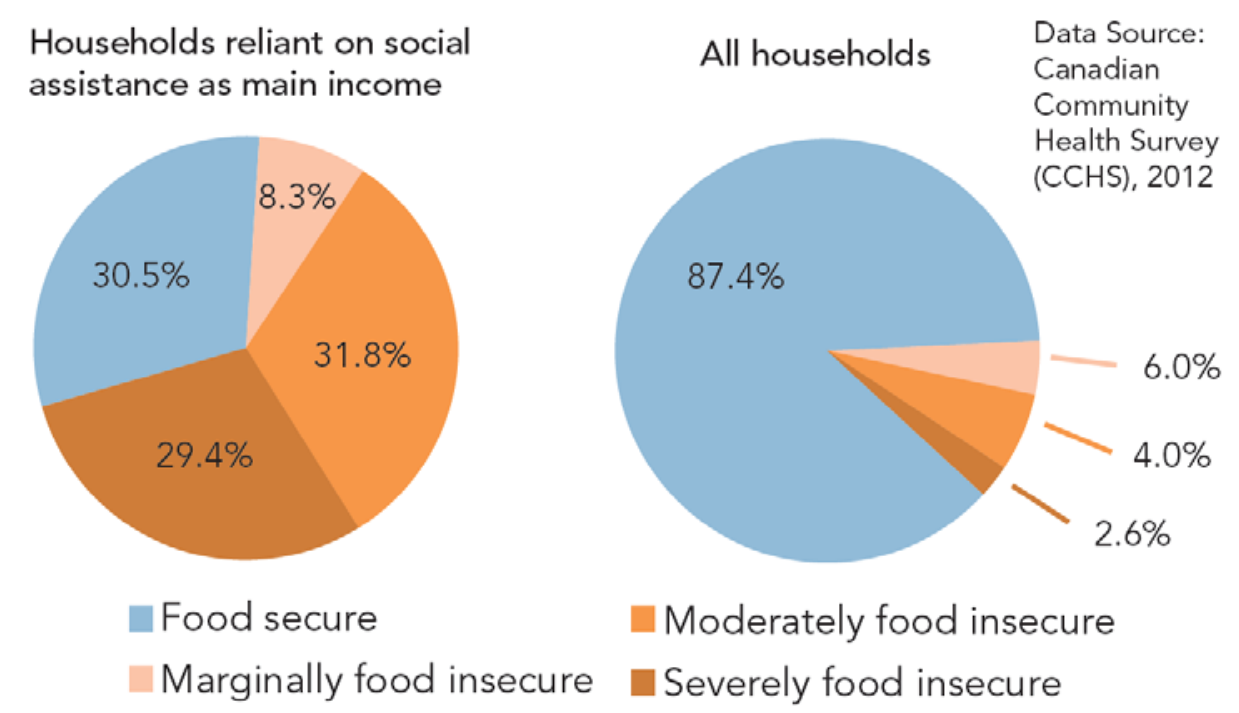


It is also imperative that the provincial and territorial governments be actively engaged in any comprehensive policy response to food insecurity because of their responsibility for minimum wages and programs such as social assistance. Although there is considerable interjurisdictional variation in the design and delivery of social assistance programs, nationally, 70 percent of households reliant on social assistance in 2012 reported food insecurity, with 29 percent reporting severe food insecurity ( Tarasuk et al., 2014) (Figure 4) (a rate that is more than 10 times the national prevalence of severe food insecurity). Addressing food insecurity requires the commitment and coordinated actions of all levels of government.

A national food policy must also include the establishment of performance targets and mechanisms for ongoing monitoring and evaluation to ensure that the policies and programs implemented under the guise of food insecurity reduction actually achieve these goals. The continued monitoring of household food insecurity through the inclusion of the Household Food Security Survey Module on the Canadian Community Health Survey is an effective means to track the progress of efforts to address this problem in the general population. As the research on household food insecurity in Canada has already demonstrated, this measure is highly policysensitive. However, the current practice of permitting provinces and territories to opt out of food insecurity measurement on some survey cycles has resulted in sporadic measurement in most jurisdictions. National, annual measurement is required to inform policy interventions and effectively track progress towards the goals of national food policy. Additionally, it will be important to implement appropriate food insecurity monitoring in First Nations communities to support the development and ongoing evaluation of interventions to reduce food insecurity among this highly vulnerable group.

In conclusion, addressing household food insecurity in Canada is a necessary prerequisite to achieving the articulated vision of national food policy. Building on the vast body of evidence that now exists, an action plan for effective policy intervention to reduce, and ultimately eradicate, household food insecurity needs to be a core element of national food policy. Given the cross-cutting nature of this issue, effective intervention will require horizontal and vertical policy integration, engaging other federal departments and all three levels of government. In addition, national food policy should include performance targets and mechanisms for ongoing monitoring and evaluation to ensure that the policies and programs implemented to reduce household food insecurity actually achieve this goal.

Acknowledgement: This research was supported by a Programmatic Grant in Health and Health Equity from the Canadian Institutes of Health Research (CIHR) (FRN 115208).

\section{References}

Action Canada. (2013/14). Hunger in Nunavut: Local Food for Healthier Communities. Retrieved from http://www.actioncanada.ca/project/hunger-nunavut-local-food-healthiercommunities/ 
Agriculture and Agri-Food Canada. (1998). Canada’s Action Plan for Food Security: A Response to the World Food Summit (1987E). Retrieved from Ottawa ON: http://publications.gc.ca/collections/collection_2013/aac-aafc/A2-190-1999-eng.pdf

Anema, A., Chan, K., Weiser, S., Montaner, J., \& Hogg, R. (2013). Relationship between food insecurity and mortality among HIV-positive injection drug users receiving antiretroviral therapy in British Columbia, Canada. PLoS One, 8(5), e61277.

Beagan, B., Chapman, G., \& Power, E. (2017). The visible and invisible occupations of food provisioning in low income families. Journal of Occupational Science, 12 pages. doi:http://dx.doi.org/10.1080/14427591.2017.1338192

Charlebois, S., von Massow, M., Tapon, F., van Duren, E., Uys, P., Pinto, W., \& Wumman, A. (2014). Food Price Report 2015. Retrieved from Guelph ON: http://foodinstitute.ca/wpcontent/uploads/2016/08/Food-Price-Report-2015.pdf

Che, J., \& Chen, J. (2001). Food insecurity in Canadian households. Health Reports, 12(4), 11-22.

Council of Canadian Academies. (2014). Aboriginal Food Security in Northern Canada: an Assessment of the State of Knowledge. Retrieved from Ottawa ON: http://www.scienceadvice.ca/uploads/eng/assessments percent20and percent20publicationspercent20and percent20news percent20releases/foodpercent20security/foodsecurity fullreporten.pdf

Cox, J., Hamelin, A. M., McLinden, T., Moodie, E., Anema, A., Rollet-Kurhajec, K., .. . Canadian Co-infection Cohort Investigators. (2016). Food insecurity in HIV-hepatitis C virus co-infected individuals in Canada: The importance of co-morbidities. AIDS and Behavior, 21(3), 792-802.

Dachner, N., Ricciuto, L., Kirkpatrick, S., \& Tarasuk, V. (2010). Food purchasing and food insecurity among low-income families in Toronto. Canadian Journal of Dietetic Practice and Research, 71(3), e50-e56.

Danyliw, A., Vatanparast, H., Nikpartow, N., \& Whiting, S. J. (2011). Beverage intake patterns of Canadian children and adolescents. Public Health Nutrition, 14(11), 1961-1969.

Davison, K., Marshall-Fabien, G., \& Tecson, A. (2015). Association of moderate and severe food insecurity with suicidal ideation in adults: National survey data from three Canadian provinces. Social Psychiatry and Psychiatric Epidemiology, 50(6), 963-972.

Egeland, G., Johnson-Down, L., Cao, Z., Sheikh, N., \& Weiler, H. (2011). Food insecurity and nutrition transition combine to affect nutrient intakes in Canadian Arctic communities. Journal of Nutrition, 141(9), 1746-1753. 
Egeland, G., Pacey, A., Cao, Z., \& Sobol, I. (2010). Food insecurity among Inuit preschoolers: Nunavut Inuit Child Health Survey, 2007-2008. Canadian Medical Association Journal, 182(3), 243-248.

Emery, J., Bartoo, A., Matheson, J., Ferrer, A., Kirkpatrick, S., Tarasuk, V., \& McIntyre, L. (2012). Evidence of the association between household food insecurity and heating cost inflation in Canada, 1998-2001. Canadian Public Policy, 38(2), 181-215.

Emery, J. H., Fleisch, V., \& McIntyre, L. (2013). Legislated changes to federal pension income in Canada will adversely affect low income seniors' health. Preventive Medicine, 57, 963-966.

Engler-Stringer, R., \& Berenbaum, S. (2005). Collective kitchens in Canada: A review of the literature. Canadian Journal of Dietetic Practice and Research, 66(4), 246-251.

Engler-Stringer, R., \& Berenbaum, S. (2007). Exploring food security with collective kitchens participants in three Canadian cities. Qualitative Health Research, 17(1), 75-84.

Engler-Stringer, R., Stringer, B., \& Haines, T. (2011). Complexity of food preparation and food security status in low-income young women. Canadian Journal of Dietetic Practice and Research, 72, 133-136.

Faught, E., Williams, P., Willows, N., Asbridge, M., \& Veugelers, P. J. (2017). The association between food insecurity and academic achievement in Canadian school-aged children. Public Health Nutrition, 20(15), 2778-2785.

First Nations Information Governance Centre (FNIGC). (2012). First Nations Regional Health Survey (RHS) 2008/10: National report on adults, youth and children living in First Nations communities. Retrieved from Ottawa ON:

http://www.fnigc.ca/sites/default/files/First percent20Nations percent20Regional percent20Health percent20Survey percent20(RHS) percent202008-10 percent20percent20National percent20Report.pdf

Fitzpatrick, T., Rosella, L., Calzavara, A., Petch, J., Pinto, A., Manson, H., . . Wodchis, W. (2015). Looking beyond income and education: Socioeconomic status gradients among future high-cost users of health care. American Journal of Preventive Medicine, 49(2), 161-171.

Ford, J., \& Beaumier, M. (2011). Feeding the family during times of stress: Experience and determinants of food insecurity in an Inuit community. The Geographical Journal, 177(1), 44-61.

Frank, L. (2015). The breastfeeding paradox: A critique of policy related to infant food insecurity in Canada. Food, Culture, and Society, 18(1), 107-129. 
Galloway, T. (2014). Is the Nutrition North Canada retail subsidy program meeting the goal of making nutritious and perishable food more accessible and affordable in the North? Canadian Journal of Public Health, 105(5), 3.

Galloway, T. (2017). Canada's northern food subsidy Nutrition North Canada: a comprehensive program evaluation. International Journal of Circumpolar Health, 76(2).

Government of Canada (last updated 21 Dec 2016). Agriculture and Agri-Food Canada. Retrieved from http://www.agr.gc.ca/eng/about-us/what-we-do/?id=1360700688523

Government of Ontario. (2017, August 23, 2017). Ontario Basic Income Pilot. Retrieved from Retrieved from https://www.ontario.ca/page/ontario-basic-income-pilot\#section-10

Gregory, C., \& Coleman-Jensen, A. (2013). Do high food prices increase food insecurity in the United States? Applied Economic Perspectives and Policy, 35(4), 679-707.

Gucciardi, E., DeMelo, M., J, V., \& Stewart, D. (2009). Exploration of the relationship between household food insecurity and diabetes care in Canada. Diabetes Care, 32, 2218-2224.

Guo, B. (2011). Household assets and food security: Evidence from the Survey of Program Dynamics. Journal of Family and Economic Issues, 32, 98-110.

Hamelin, A. M., Beaudry, M., \& Habicht, J.-P. (2002). Characterization of household food insecurity in Quebec: Food and feelings. Social Science \& Medicine, 54(1), 119-132.

Hamelin, A. M., Mercier, C., \& Bedard, A. (2010). Discrepancies in households and other stakeholders viewpoints on the food security experience: A gap to address. Health Education Research, 25(3), 401-412.

Hamelin, A. M., Mercier, C., \& Bedard, A. (2011). Needs for food security from the standpoint of Canadian households participating and not participating in community food programmes. International Journal of Consumer Studies, 35, 58-68.

Health Canada. (2007). Canadian Community Health Survey, Cycle 2.2, Nutrition (2004) Income-Related Household Food Security in Canada (4696). Retrieved from Ottawa ON: https://www.canada.ca/en/health-canada/services/food-nutrition/food-nutritionsurveillance/health-nutrition-surveys/canadian-community-health-survey-cchs/canadiancommunity-health-survey-cycle-2-2-nutrition-2004-income-related-household-foodsecurity-canada-health-canada-2007.html

Huang, J., Guo, B., \& Kim, Y. (2010). Food insecurity and disability: Do economic resources matter? Social Science Research, 39, 111-124.

Huet, C., Rosol, R., \& Egeland, G. (2012). The prevalence of food insecurity is high and the diet quality poor in Inuit communities. Journal of Nutrition, 142, 541-547. 
Huisken, A., Orr, S., \& Tarasuk, V. (2016). Adults’ food skills and use of gardens are not associated with household food insecurity in Canada. Canadian Journal of Public Health, 107(6), e526-e532.

Ionescu-Ittu, R., Glymour, M., \& Kaufman, J. (2015). A difference-in-difference approach to estimate the effect of income-supplementation on food insecurity. Preventive Medicine, 70, 108-116.

Jessiman-Perreault, G., \& McIntyre, L. (2017). The household food insecurity gradient and potential reductions in adverse population mental health outcomes in Canadian adults. SSM -Population Health, 3, 464-472.

Kirk, S., Kuhle, S., McIsaac, J., Williams, P. L., Rossiter, M., Ohinmaa, A., \& Veugelers, P. (2014). Food security status among grade 5 students in Nova Scotia, Canada and its associations with health outcomes. Public Health Nutrition, 18(16), 2943-2951.

Kirkpatrick, S., Dodd, K. W., Parsons, R., Ng, C., Garriguet, D., \& Tarasuk, V. (2015). Household food insecurity is a stronger marker of adequacy of nutrient intakes among Canadian compared to American youth and adults. Journal of Nutrition, 145(7), 15961603.

Kirkpatrick, S., McIntyre, L., \& Potestio, M. (2010). Child hunger and long-term adverse consequences for health. Archives of Pediatrics \& Adolescent Medicine, 164(8), 754-762.

Kirkpatrick, S., \& Tarasuk, V. (2008). Food insecurity is associated with nutrient inadequacies among Canadian adults and adolescents. Journal of Nutrition, 138, 604-612.

Kirkpatrick, S., \& Tarasuk, V. (2010). Assessing the relevance of neighbourhood characteristics to the household food security of low-income Toronto families. Public Health Nutrition, 13(7), 1139-1148.

Lambden, J., Receveur, O., Marshall, J., \& Kuhnlein, H. (2006). Traditional and market food access in Arctic Canada is affected by economic factors. International Journal of Circumpolar Health, 65(4), 331-340.

Leete, L., \& Bania, N. (2010). The effect of income shocks on food insufficiency. Review of Economics of the Household, 8(4), 505-526.

Li, N., Dachner, N., \& Tarasuk, V. (2016). The impact of changes in social policies on household food insecurity in British Columbia, 2005-2012. Preventive Medicine, 93, 151-158.

Loopstra, R., Dachner, N., \& Tarasuk, V. (2015). An exploration of the unprecedented decline in the prevalence of household food insecurity in Newfoundland and Labrador, 2007-2012. Canadian Public Policy, 41(3), 191-206. 
Loopstra, R., \& Tarasuk, V. (2013). Perspectives on community gardens, community kitchens and the Good Food Box program in a community-based sample of low-income families. Canadian Journal of Public Health, 104(1), e55-e59.

Loopstra, R., \& Tarasuk, V. (2015). Food bank use is a poor indicator of food insecurity: insights from Canada. Social Policy and Society, 14(3), 443-455.

MacRae, R. (2011). A joined-up food policy for Canada. Journal of Hunger and Environmental Nutrition, 6(4), 424-457.

Mah, C., Hamill, C., Rondeau, K., \& McIntyre, L. (2014). A frame-critical policy analysis of Canada's response to the World Food Summit 1998-2008. Archives of Public Health, 72(41).

Marjerrison, S., Cummings, E., Glanville, N. T., Kirk, S., \& Ledwell, M. (2010). Prevalence and associations of food insecurity in children with diabetes mellitus. Journal of Pediatrics, 158(4), 607-611.

Mark, S., Lambert, M., O'Loughlin, J., \& Gray-Donald, K. (2012). Household income, food insecurity and nutrition in Canadian youth. Canadian Journal of Public Health/Revue Canadienne de Sante'e Publique, 103(2), 94-99.

McIntyre, L., Bartoo, A., \& Emery, J. (2012). When working is not enough: Food insecurity in the Canadian labour force. Public Health Nutrition, 17(1), 49-57.

McIntyre, L., Connor, S. K., \& Warren, J. (2000). Child hunger in Canada: Results of the 1994 National Longitudinal Survey of Children and Youth. Canadian Medical Association Journal, 163(8), 961-965.

McIntyre, L., Dutton, D., Kwok, C., \& Emery, J. (2016a). Reduction of food insecurity in lowincome Canadian seniors as a likely impact of a Guaranteed Annual Income. Canadian Public Policy, 42(3), 274-286.

McIntyre, L., Glanville, N. T., Raine, K. D., Dayle, J. B., Anderson, B., \& Battaglia, N. (2003). Do low-income lone mothers compromise their nutrition to feed their children?. Canadian Medical Association Journal, 168(6), 686-691.

McIntyre, L., Kwok, C., \& Patten, S. (2017). The effect of child hunger on educational attainment and early childbearing outcomes in a longitudinal population sample of Canadian youth. Pediatrics \& Child Health, 1-8.

McIntyre, L., Lukic, R., Patterson, P., Anderson, L., \& Mah, C. (2016b). Legislation debated as responses to household food insecurity in Canada, 1995-2012. Journal of Hunger and Environmental Nutrition, 11(4), 441-455. 
McIntyre, L., Patterson, P., Anderson, L., \& Mah, C. (2016c). Household food insecurity in Canada: problem definition and potential solutions in the public policy domain. Canadian Public Policy, 42(1), 83-93.

McIntyre, L., Wu, X., Fleisch, V., \& Emery, J. (2015). Homeowner versus non-homeowner differences in household food insecurity in Canada. Journal of Housing and the Built Environment, 31(2), 349-366.

McIntyre, L., Wu, X., Kwok, C., \& Patten, S. B. (2017). The pervasive effect of youth self-report of hunger on depression over 6 years of follow up. Social psychiatry and psychiatric epidemiology, 52(5), 537-547.

Melchior, M., Chastang, J., Falissard, B., Galera, C., Tremblay, R., Cote, S., \& Boivin, M. (2012). Food insecurity and children's mental health: A prospective birth cohort study. PLoS One, 7(12), e52615.

Muldoon, K., Duff, P., Fielden, S., \& Anema, A. (2012). Food insufficiency is associated with psychiatric morbidity in a nationally representative study of mental illness among food insecure Canadians. Social Psychiatry and Psychiatric Epidemiology, 48(5), 795-803.

Nord, M., Coleman-Jensen, A., \& Gregory, C. (2014). Prevalence of U.S. Food Insecurity Is Related to Changes in Unemployment, Inflation, and the Price of Food (ERR-167). Retrieved from https://www.ers.usda.gov/publications/pub-details/?pubid=45216

Office of the Prime Minister. (2015). Minister of Agriculture and Agri-Food Mandate Letter. Retrieved from http://pm.gc.ca/eng/minister-agriculture-and-agri-food-mandate-letter

Perez, E., Roncarolo, F., \& Potvin, L. (2017). Associations between the local food environment and the severity of food insecurity among new families using community food security interventions in Montreal. Canadian Journal of Public Health, 108(1), e49-e55.

Pirkle, C., Lucas, M., Dallaire, R., Ayotte, P., Jacobso, J., Jacobson, S., . . Muckle, G. (2014). Food insecurity and nutritional biomarkers in relation to stature in Inuit children from Nunavik. Canadian Journal of Public Health, 105(4), e233-e238.

PROOF. (2017). Food insecurity and social assistance [fact sheet]. Retrieved from: http://proof.utoronto.ca/resources/fact-sheets/\#socialassistance.

PROOF. (2018). Household food insecurity in Canada. Retrieved from: http://proof.utoronto.ca/food-insecurity/

Province of Newfoundland and Labrador. (2014). Newfoundland and Labrador Poverty Reduction Strategy Progress Report. Retrieved from http://www.cssd.gov.nl.ca/poverty/pdf/prs_progress_report.pdf 
Rollin, A. (2013). The increase in food prices between 2007 and 2012 (027). Retrieved from http://www.statcan.gc.ca/pub/11-626-x/11-626-x2013027-eng.htm

Seed, B., Lang, T., Caraher, M., \& Ostry, A. (2014). Exploring Public Health’s roles and limitations in advancing food security in British Columbia. Canadian Journal of Public Health, 105(5), e324-329.

Sriram, U., \& Tarasuk, V. (2015). Changes in household food insecurity rates among Census metropolitan areas from 2007 to 2012. Canadian Journal of Public Health, 106(5), e322-e327.

Sriram, U., \& Tarasuk, V. (2016). Economic predictors of household food insecurity in Canadian metropolitan areas. Journal of Hunger and Environmental Nutrition, 11, 1-13.

Statistics Canada. (2008). Canadian Community Health Survey (CCHS), 2007: Annual component [data file]. Available from: http://www23.statcan.gc.ca/imdb/p2SV.pl?Function=getSurvey\&Id=29539

Statistics Canada. (2009). Canadian Community Health Survey (CCHS), 2008: Annual component [data file]. Available from: http://www23.statcan.gc.ca/imdb/p2SV.pl?Function=getSurvey\&Id=56918

Statistics Canada. (2012). Canadian Community Health Survey (CCHS), 2011: Annual component [data file]. Available from: http://www23.statcan.gc.ca/imdb/p2SV.pl?Function=getSurvey\&Id=114112

Statistics Canada. (2013). Canadian Community Health Survey (CCHS), 2012: Annual component [data file]. Available from: http://www23.statcan.gc.ca/imdb/p2SV.pl?Function=getSurvey\&Id=135927

Tarasuk, V. (2001). A critical examination of community-based responses to household food insecurity in Canada. Health Education \& Behavior, 28(4), 487-499.

Tarasuk, V., Cheng, J., de Oliveira, C., Dachner, N., Gundersen, C., \& Kurdyak, P. (2015). Association between household food insecurity and annual health care costs. Canadian Medical Association Journal, 187(14), E429-E436.

Tarasuk, V., Cheng, J., Gundersen, C., De Oliveira, C., \& Kurdyak, P. (2018). The relation between food insecurity and mental health service utilization in Ontario. Canadian Journal of Psychiatry, 63(8), 557-569.

Tarasuk, V., Mitchell, A., \& Dachner, N. (2014). Household food insecurity in Canada, 2012. Retrieved from http://proof.utoronto.ca/

Tarasuk, V., Mitchell, A., \& Dachner, N. (2016). Household Food Insecurity in Canada, 2014. Retrieved from http://proof.utoronto.ca/ 
Tarasuk, V., Mitchell, A., McLaren, L., \& McIntyre, L. (2013). Chronic physical and mental health conditions among adults may increase vulnerability to household food insecurity. Journal of Nutrition, 143(11), 1785-1793.

Tarasuk, V., \& Vogt, J. (2009). Household food insecurity in Ontario. Canadian Journal of Public Health/Revue Canadienne de Sante'e Publique, 184-188.

Vatanparast, H., Calvo, M., Green, T. J., \& Whiting, S. J. (2010). Despite mandatory fortification of staple foods, vitamin D intakes of Canadian children and adults are inadequate. Journal of Steroid Biochemistry \& Molecular Biology, 121, 301-303.

Veeraraghavan, G., Martin, D., Burnett, K., Jamal, A., Skinner, K., Ramsay, M., ... Stothart, C. (2016). Paying for Nutrition. A Report on Food Costing in the North. Retrieved from https://foodsecurecanada.org/sites/foodsecurecanada.org/files/201609_paying_for_nutritio n_fsc_report_final_wt_erratum.pdf

Vozoris, N., \& Tarasuk, V. (2003). Household food insufficiency is associated with poorer health. Journal of Nutrition, 133(1), 120-126.

Weiler, A., McLauglin, J., \& Cole, D. (2017). Food security at whose expense? A critique of the Canadian temporary farm labour migration regime and proposals for change. International Migration, 55(4), 48-63.

Williams, P. L., Macaulay, R., Anderson, B. J., Barro, K., Gillis, D., Johnson, C. P., ... Reimer, D. (2012). "I would have never thought that I would be in such a predicament": voices from women experiencing food insecurity in Nova Scotia, Canada. Journal of Hunger and Environmental Nutrition, 7, 253-270.

Willows, N., Veugelers, P., Raine, K., \& Kuhle, S. (2011). Associations between household food insecurity and health outcomes in the Aboriginal population (excluding reserves). Health Rep, 22(2), 1-6. http://www.statcan.gc.ca/pub/82-003-x/2011002/article/11435-eng.pdf

Willows, N. D., Veugelers, P., Raine, K., \& Kuhle, S. (2009). Prevalence and sociodemographic risk factors related to household food insecurity in Aboriginal peoples in Canada. Public Health Nutrition, 12(8), 1150-1156.

Wong, A., \& Hallsworth, A. (2016). Local food security initiatives: systemic limitations in Vancouver, Canada. Future of Food: Journal on Food, Agriculture and Society, 4(1), 7-28. 